\title{
Combined precut in difficult biliary cannulation
}

\author{
Jesús Espinel-Díez ${ }^{1}$, Eugenia Pinedo-Ramos ${ }^{2}$, Luis Vaquero-Ayala ${ }^{1}$, Begoña Álvarez-Cuenllas ${ }^{1}$ \\ and Vanesa Ojeda-Marrero ${ }^{3}$
}

\begin{abstract}
${ }^{1}$ Department of Digestive Diseases. Hospital de León. León, Spain. ${ }^{2}$ Department of Radiodiagnosis. Hospital de León. León, Spain. ${ }^{3}$ Department of Digestive Diseases. Hospital Universitario Dr. Negrín. Las Palmas de Gran Canaria, Spain
\end{abstract}

\begin{abstract}
Aim: precut sphincterotomy refers to a variety of endoscopic techniques that are used in order to access the bile duct when conventional methods of cannulation have failed. There are not significant data (such as efficacy, safety) about the use of different techniques of precutting at the same session. We have described our experience with combined precut sphincterotomy (CPS) and we have compared our results to the use of an isolated precut.

Patients and methods: we have performed 247 precuts of a total of 2.390 ERCPs. Patients were distributed according to the type of precut practiced: Needle-knife, transpancreatic and combined precut sphincterotomies. "Combined precut" consisted in performing first a transpancreatic sphincterotomy and, if the access was not achieved, then performing a needle-knife sphincterotomy in the same session. The data about safety and efficacy were prospectively collected. The complications were defined according to the consensus criteria.

Results: we performed precutting techniques in 247 patients. Needle-knife, transpancreatic, and combined precuts were performed in 125 (6.9\%), 74 (4.1\%) and 48 (2.6\%) patients, respectively. Bile duct cannulation was successful in 48 patients $(100 \%)$ in the group of combined precut, 121 patients $(96.8 \%)$ in the transpancreatic group, and 67 patients (90.5\%) in the needleknife group $(p=0.03)$. There were not differences in complications rates between the three groups. There was no pancreatitis in the combined precut group. The complications were successfully managed with conservative treatment.
\end{abstract}

Conclusions: combined precut sphincterotomy seems to be a safe and successful technique in those cases of difficult bile duct cannulation.

Key words: Endoscopic retrograde cholangiopancreatography (ERCP). Precut sphincterotomy. Needle-knife sphincterotomy. Transpancreatic sphincterotomy. ERCP complications. Pancreatitis.

Received: 11-02-2013

Accepted: 15-04-2013

Correspondence: Jesús Espinel Díez. Department of Digestive Diseases. Hospital de León. Altos de Nava, s/n. 24071 León. Spain e-mail: espinel.jesus@gmail.com

\section{INTRODUCTION}

Precut sphincterotomy refers to a variety of endoscopic techniques used to gain access to the bile duct when conventional methods of cannulation have failed. Use of precut sphincterotomy varied from none to as many as $38 \%$ of all biliary cannulation attempts in different reports (1-8). Use of precut sphincterotomy is highly controversial, with widely variable opinions as to its appropriateness, safety, and preferred technique. The most widely practiced technique is the free-hand needle-knife, in which an incision is made starting at the orifice and extending cephalad for a variable distance, or a variation of this, often referred to as fistulotomy, which involves making a puncture in the hole above the papilla, avoiding the pancreatic orifice. The second major approach involves use of a traction sphincterotome. A now more commonly used variation of this technique involves intentional seating of the tip of a standard traction sphincterotome into the pancreatic duct and cutting through the septum in the direction of the bile duct, an approach referred to as "transpancreatic sphincterotomy" (TPS). Our precut sphincterotomy experience began with the needle-knife (NKPS) (7) although, over time, we significantly increased the use of TPS (8). There are no significant data (efficacy, safety) regarding the combined use of both techniques in the same session. The aim of our study was to assess the efficacy and safety of combined precut sphincterotomy (CPS) in comparison with other forms of precut sphincterotomy.

Espinel-Díez J, Pinedo-Ramos E, Vaquero-Ayala L, Álvarez Cuenllas B, Ojeda-Marrero V. Combined precut in difficult biliary cannulation. Rev Esp Enferm Dig 2013;105:334-337. 


\section{PATIENTS AND METHODS}

We have performed a consecutive analysis of data collected prospectively in an established database, of endoscopic precut sphincterotomies that were done for a therapeutic indication between November 2004 and June 2012. During this period, 2,390 ERCPs, 1,789 endoscopic sphincterotomies and 247 precuts were performed by an experienced endoscopist (J. E.) with a therapeutic duodenoscope (Olympus). Patients gave informed consent for participation in an ERCP. The patients were distributed according to the type of precut practiced: NKPS, TPS and, combined (CPS) precut sphincterotomies. After several attempts (more than 5) to selectively cannulate the bile duct, precut sphincterotomy was carried out. NKPS was performed with HPC-2 precut sphincterotome (Cook) using the free-hand needle-knife technique, in which the incision is made starting at the papillary orifice and extending cephalad for a variable distance. TPS was performed by placing the tip of a standard traction sphincterotome (CT-25 sphincterotome, Cook) into the pancreatic duct and cutting through the septum in the direction of the bile duct (11 o'clock) (8). Following the introduction of "CPS", when the conventional access was not archieved, the next step consisted in performing first a TPS and, if it failed, a NKPS was subsequently performed, at the same session (Figs. 1 and 2). A power generator (ERBE ICC200) was used as the power source for all precuts (Endocut mode, $120 \mathrm{~W}$, effect 2). Safety and efficacy data were prospectively collected and we included serum amylase measurement before and at 6 and 24 hours after ERCP. If ERCP failed, the procedure was repeated two to five days after. Complications (pancreatitis, hemorrhage, perforation) were diagnosed and graded with consensus criteria (9). Patients were discharged 2 days after ERCP, if no complications were detected. "Initial success" was defined as successful biliary cannulation during initial ERCP. "Second success" was defined as successful biliary cannulation in a second attempt, 2-5 days after. "Final success" was defined

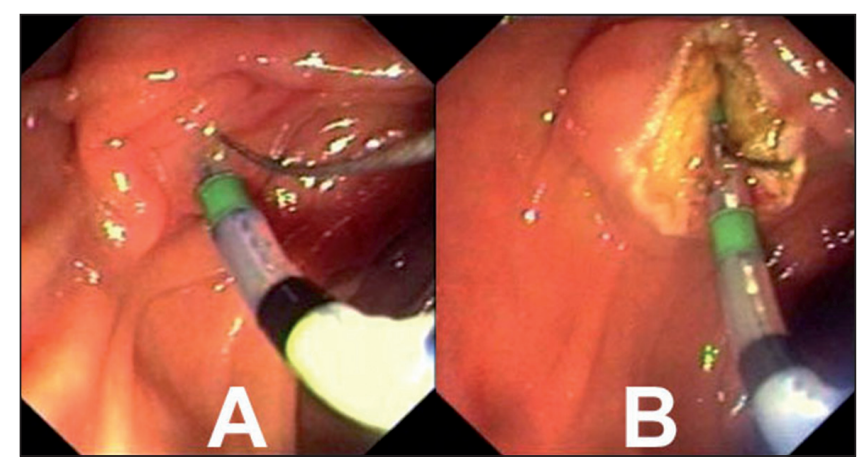

Fig. 1. Combined precut sphincterotomy. A. Transpancretic precut sphincterotomy: the sphincterotome is within the pancreatic duct. B. Transpancretic precut sphincterotomy: a clean sphincterotomy, without papillary bleeding. as successful biliary cannulation after initial \pm second success. Hyperamylasemia was defined $\geq 460$ (IU/L) (normal values: $23-154$ ). The qualitative variables were expressed as absolute number and percentage, whereas quantitative variables were expressed as mean. Chi-square statistics and Fisher's exact test were used to assess significant associations among qualitative variables. T-Student test were used to compare quantitative independent variables or Mann-Whitney U-test, when the sample is moved away from the normal distribution. A $p$ value lower than 0.05 was considered as statistically significant. All statistics were performed using the SPSS v18 for Windows Statistical package (SPSS Inc., Chicago, IL, USA).

\section{RESULTS}

A total of 247 patients ( 122 men and 125 women, mean age 74 years, range 25-93 years) underwent attempted precutting techniques (13.8\% of sphincterotomies cases, $10.3 \%$ of ERCP cases). TPS, NKPS, and CPS precuts were performed in $125(6.9 \%), 74(4.1 \%)$ and $48(2.6 \%)$ patients, respectively. Bile duct cannulation was successful in 48 patients of the CPS group (100\%) [initial success in $40(83.3 \%)$; second success in $8(16.6 \%)$ ], compared with 121 patients of the TPS group $(96.8 \%)$ [initial success in 117 (93.6\%); second success in $4(3.2 \%)]$ and 67 patients of the NKPS group (90.5\%) [initial success in $61(82.4 \%)$; second success in $6(8.1 \%)$ ] $(p=0.03)$ (Table I). The complication rates of the different groups are shown in Table I. One patient $(2.1 \%)$ of the CPS group had a complication (clinical hemorrhage) compared with 11 patients $(8.8 \%)$ of the TPS group that developed 4 pancreatitis, 6 clinical hemorrhages, 1 perforation, and 5 patients $(6.8 \%)$ of the NKPS group that developed 1 pancreatitis, 2 clinical hemorrhages, and 2 perforations $(p=0.3)$. Hyperamylasemia was evidenced in $9(18.7 \%), 33(26.4 \%)$ and $3(4.0 \%)$ patients, in CPS, TPS and NKPS group, respectively $(p=0.009)$. All complications were successfully managed

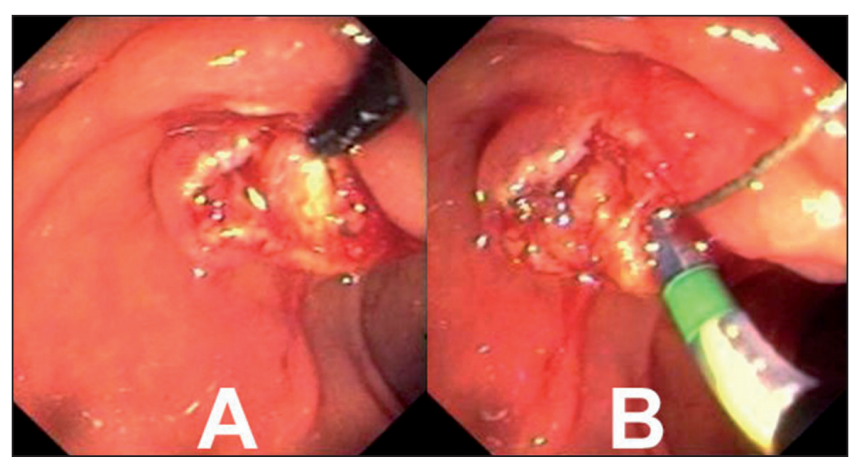

Fig. 2. Combined precut sphincterotomy. A. After the transpancretic precut sphincterotomy, it is possible to make a more safe and accurate NKPS, where the papilla protrudes. B. Subsequently, biliary cannulation is achieved with conventional sphincterotome (with guidewire). 
Table I. Results of precut techniques (success and complications)

\begin{tabular}{lllll}
\hline & CPS $n=48$ & TPS $n=125$ & NKPS $n=74$ & \\
\hline Success & & & & \\
Initial & $40(83.3 \%)$ & $117(93.6 \%)$ & $61(82.4 \%)$ & \\
Second & $8(16.6 \%)$ & $4(3.2 \%)$ & $6(8.1 \%)$ & $p=0.03$ \\
Final & $48(100 \%)$ & $121(96.8 \%)$ & $67(90.5 \%)$ & $p=n$.s. \\
\hline Complications & $1(2 \%)$ & $11(8.8 \%)$ & $5(6.8 \%)$ & \\
Bleeding & $1(2 \%)$ & $6(4.8 \%)$ & $2(2.7 \%)$ & \\
Pancreatitis & - & $4(3.2 \%)$ & $1(1.3 \%)$ & \\
Perforation & - & $1(0.8 \%)$ & $2(2.7 \%)$ & 0.009 \\
\hline Hyperamylasemia & $9(18.7 \%)$ & $33(26.4 \%)$ & $3(4 \%)$ & \\
\hline
\end{tabular}

CPS: combined precut; NKPS: needle-knife precut; TPS: transpancreatic precut.

with conservative (medical/endoscopic) treatment. There were no procedure related deaths.

\section{DISCUSSION}

Cannulation of the bile duct is a prerequisite to successful biliary therapy during ERCP. Entry into the bile duct can be difficult in some patients (5\%-20\% of ERCPs) (10). The techniques available for cannulation have expanded dramatically over the last 15 years or so, probably improving not only success rates but reducing complications as well. Standard techniques include the use of guidewires in conjunction with catheters, and sphincterotomes. Specialized techniques, include placement of pancreatic guidewire (or stent) to assist biliary cannulation (11), precut "access" sphincterotomy, suprapapillary puncture of the common bile duct (12), the use of two devices simultaneously in the same duodenoscopy channel (13), endoscopic scissors (14), blunt dissection with a cotton swab, and even to the seemingly drastic approach of performing endoscopic ampullectomy $(15,16)$. Precut techniques are often used after conventional methods of biliary cannulation have failed. The need for precut sphincterotomy was increase in malignancies and was less common in patients with bile duct stones (17). Precut techniques have proved their usefulness and safety in various studies with immediate success rates from 35 to $96 \%$ (18-20). However, there are not significant data available over combined precut sphincterotomy at the same ERCP session (20). Our study includes 48 CPS and we have compared our results to the use of an isolated precut (TPS or NKPS). CPS group had a remarkable biliary cannulation rate, with an initial success of $83.3 \%$ and a final success of $100 \%$, reaching statistical significance. Although only immediate success at cannulation represents the true success because repeat ERCP without precut may also have been effective, it is important to know that combined sphincterotomy performed by an expert endoscopist is able to achieve a biliary cannulation over 99 percent of the cases during the first or the second attempt, with very few complications. Complications have been reported in 2 to 34 percent of precuts, a rate that is generally higher than reported patients undergoing standard sphincterotomy (1,21-25). Some complications have been unusual $(26,27)$. Precutting is an independent risk factor for overall complications, particularly for post-ERCP pancreatitis (4,28-30) and perforation (23). Complications associated with ERCP, depend upon patient-related factors, as well as technique and operator characteristics. Placement of a pancreatic stent (small caliber: 3 or 4 French) may be advisable in higher risk patients undergoing precut techniques (29). However, it may sometimes be difficult to place a pancreatic stent even by an experienced endoscopist and, it may lead to a worse outcome than if no attempt is made. Pancreatic stent may lead to serious adverse events, including misplacement inside the duct, inward migration, and pancreatic ductal injury. Pancreatic stent placement adds substantial cost and inconvenience to the patient and health care system (radiographic studies to document passage, repeat endoscopy for removal) (31). Also, it is still debated whether complications of precut are due to the precut itself or the antecedent cannulation attempt. A study (meta-analysis) (32) concludes that postERCP pancreatitis was significantly less common in the precut group compared with the persistent attempts at cannulation group ( 3 versus 5 percent). Our study shows rates of post-ERCP pancreatitis between $1.5 \%$ (NKPS group) and $3.2 \%$ (TPS group), however there was not pancreatitis in the CPS group. These low pancreatitis rates, without prophylactic pancreatic stent placement, may be in part due to the use of an early precut (after 5 attempts, precut was carried out), the high volume of therapeutic ERCPs in our center, and the skill or endoscopist's experience. Hyperamylasemia was significantly less common in the NKPS group compared with the other groups, and it could be explained because the patients with TPS and CPS have more pancreatic guidewire entrances. Nevertheless, there 
were no statistical significant differences in the pancreatitis rate between the groups. Success and complication rates of CPS are hopeful. It is possible that the great results obtained with the CPS are due to those advantages:

1.TPS allows to perform the precut with the same sphincterotome with initiating cannulation, without exchange accessories. Moreover the depth of the incision is controlled, so the perforation's risk will be lower. 2 . TPS usually gets a clean sphincterotomy, without papillary bleeding. 3 . Therefore that can make easier the identification of the exposed bile duct orifice, so it can get an immediate cannulation, or 4. It can provide an anatomical guide in order to find the bile's duct location, allowing for a safer and accurate needle-knife sphincterotomy where the papilla protrudes.

Endoscopists must have familiarity with precut sphincterotomy techniques, and they have to choose the most appropriate technique in agreement with individual patient's anatomy and their risk profile. CPS seems to be a safe and successful technique in those cases of difficult bile duct cannulation when it is performed by an experienced endoscopist.

\section{REFERENCES}

1. Akashi R, Kiyozumi T, Jinnouchi K, Yoshida M, Adachi Y, Sagara K. Pancreatic sphincter precutting to gain selective access to the common bile duct: a series of 172 patients. Endoscopy 2004;36:405-10.

2. Bruins Slot W, Schoeman MN, Disario JA, Wolters F, Tytgat GN, Huibregtse K. Needle-knife sphincterotomy as a precut procedure: a retrospective evaluation of efficacy and complications. Endoscopy 1996;28:334-9.

3. Dowsett JF, Polydorou AA, Vaira D, D'Anna LM, Ashraf M, Croker $\mathrm{J}$, et al. Needle knife papillotomy: how safe and how effective? Gut 1990;31:905-8.

4. Freeman ML, Nelson DB, Sherman S, Haber GB, Herman ME, Dorsher PJ, et al. Complications of endoscopic biliary sphincterotomy. $\mathrm{N}$ Engl J Med 1996;335:909-18.

5. Harewood GC, Baron TH. An assessment of the learning curve for precut biliary sphincterotomy. Am J Gastroenterol 2002;97:1708-12.

6. Rabenstein T, Ruppert T, Schneider HT, Hahn EG, Ell C. Benefits and risks of needle-knife papillotomy. Gastrointest Endosc 1997;46:207-11.

7. Espinel J, Vivas S, Muñoz F, Domínguez A, Villanueva R, Jorquera F, et al. Esfinterotomía de aguja como técnica de acceso a la vía biliar: estudio prospectivo. Gastroenterol Hepatol 2005;28:369-74.

8. Espinel J. Acceso a la vía biliar mediante esfinterotomía transpancreática. Gastroenterol Hepatol 2006;29:281-5.

9. Cotton PB, Lehman G, Vennes J, Geenen JE, Russell RC, Meyers WC, et al. Endoscopic sphincterotomy complications and their management: an attempt at consensus. Gastrointest Endosc 1991;37:383-93.

10. Siegel JH, Ben-Zvi JS, Pullano W. The needle knife: a valuable tool in diagnostic and therapeutic ERCP. Gastrointest Endosc 1989;35:499-503.

11. Herreros de Tejada A, Calleja JL, Díaz G, Pertejo V, Espinel J, Cacho $\mathrm{G}$, et al. Double-guidewire technique for difficult bile duct cannulation: a multicenter randomized, controlled trial. Gastrointest Endosc 2009;70:700-9.
12. Artifon EL, Sakai P, Ishioka S, Hondo FY, Raju GS. Suprapapillary puncture of the common bile duct for selective biliary access: a novel technique. Gastrointest Endosc 2007;65:124-31.

13. Espinel J, Pinedo E. Two-sphincterotomes-in-one-channel method: help in cannulation and sphincterotomy. Rev Esp Enferm Dig 2011;103:375-6.

14. Heiss FW, Cimis RS Jr, MacMillan FP Jr. Biliary sphincter scissor for pre-cut access: preliminary experience. Gastrointest Endosc 2002;55:719-22.

15. Freeman ML, Guda NL. Cannulation techniques for ERCP: a review of reported techniques. Gastrointest Endosc 2005;61:112-25.

16. Farrell RJ, Khan MI, Noonan N, O'Byrne K, Keeling PW. Endoscopic papillectomy: a novel approach to difficult cannulation. Gut 1996;39:36-8.

17. Linder S, Söderlund C. Factors influencing the use of precut technique at endoscopic sphincterotomy. Hepatogastroenterology 2007;54:2192-7.

18. Kapetanos D, Kokozidis G, Christodoulou D, Mistakidis K, Dimakopoulos K, Katodritou E, et al. Case series of transpancreatic septotomy as precutting technique for difficult bile duct cannulation. Endoscopy 2007;39:802-6

19. Weber A, Roesch T, Pointner S, Born P, Neu B, Meining A, et al Transpancreatic precut sphincterotomy for cannulation of inaccessible common bile duct: a safe and successful technique. Pancreas 2008;36:187-91.

20. Halttunen J, Keränen I, Udd M, Kylänpää L. Pancreatic sphincterotomy versus needle knife precut in difficult biliary cannulation. Surg Endosc 2009;23:745-9.

21. Goff JS. Common bile duct pre-cut sphincterotomy: transpancreatic sphincter approach. Gastrointest Endosc 1995;41:502-5.

22. Goff JS. Long-term experience with the transpancreatic sphincter pre-cut approach to biliary sphincterotomy. Gastrointest Endosc 1999;50:642-5

23. Mavrogiannis C, Liatsos C, Romanos A, Petoumenos C, Nakos A, Karvountzis G. Needle-knife fistulotomy versus needle-knife precut papillotomy for the treatment of common bile duct stones. Gastrointest Endosc 1999;50:334-9.

24. Lehman GA, Sherman S. Pancreatic stones: to treat or not to treat? Gastrointest Endosc 1996;43:625-6.

25. Catalano MF, Linder JD, Geenen JE. Endoscopic transpancreatic papillary septotomy for inaccessible obstructed bile ducts: Comparison with standard pre-cut papillotomy. Gastrointest Endosc 2004;60:557-61

26. Espinel J, Pinedo ME, Calleja JL. Portal vein filling: an unusual complication of needle-knife sphincterotomy. Endoscopy 2007;39(Suppl 1):E245.

27. Espinel J, Pinedo E, Rascarachi G, Bailador C. Exceptional vascular complication during ERCP: cannulation of the hepatic artery. Rev Esp Enferm Dig 2011;103:164-5.

28. Loperfido S, Angelini G, Benedetti G, Chilovi F, Costan F, De Berardinis F, et al. Major early complications from diagnostic and therapeutic ERCP: a prospective multicenter study. Gastrointest Endosc 1998;48:1-10.

29. Freeman ML, Guda NM. Prevention of post-ERCP pancreatitis: a comprehensive review. Gastrointest Endosc 2004;59:845-64.

30. Masci E, Mariani A, Curioni S, Testoni PA. Risk factors for pancreatitis following endoscopic retrograde cholangiopancreatography: a metaanalysis. Endoscopy 2003;35:830-4.

31. Abu Dayyeh BK. Prophylactic main pancreatic duct stenting before precut biliary sphincterotomy: hold on to what you've got. Gastrointest Endosc 2013;77:217-8.

32. Cennamo V, Fuccio L, Zagari RM, Eusebi LH, Ceroni L, Laterza L, et al. Can early precut implementation reduce endoscopic retrograde cholangiopancreatography-related complication risk? Meta-analysis of randomized controlled trials. Endoscopy 2010;42:381-8. 